\title{
Meningkatkan Service Quality Usaha Laundry Menggunakan Throw-Away Prototyping
}

\author{
Mayadi*1 $^{1}$, Rakhmi Khalida ${ }^{2}$, Siti Setiawati ${ }^{3}$ \\ ${ }^{1,2,3}$ Universitas Bhayangkara Jakarta Raya; J1. Perjuangan No.81 Marga Mulya Bekasi, (021) \\ 88955882 \\ e-mail:*1'mayadi@dsn.ubharajaya.ac.id , 2rakhmi.khalida@dsn.ubharajaya.ac.id, \\ ${ }^{3}$ siti.setiawati@dsn.ubharajaya.ac.id
}

\begin{abstract}
Abstrak
Banyaknya persaingan bisnis jasa laundry membuat pemilik laundry harus mengambil kebijakan untuk kemajuan usaha. Dalam hal pengolahan data, usaha laundry tidak terlalu mementingkan manajemen data baik dalam hal transaksi data pelanggan atau penyerahan barang pelanggan. Manajemen data yang belum sistematis juga menyebabkan sering terjadi kekeliruan dalam pembukuan. Tujuan penelitian ini yaitu dapat merancang sistem informasi jasa laundry berbasis web untuk membantu meningkatkan kinerja pada admin dalam pembuatan laporan, dan membuat pemberitahuan bagi pelanggan dengan SMS gateway saat pakaiannya telah selesai dikerjakan. Pembuatan sistem informasi jasa laundry berbasib web ini menggunakan metode pengembangan software throw-away prototyping dengan tahapan analisis kebutuhan, pembuatan prototype, evaluasi prototype, spesifikasi system, program sistem, validasi system, dan instalasi aplikasi. Dalam pembuatan sistem informasi jasa laundry berbasi web ini menggunakan metode pengumpulan data dilakukan wawancara, studi literature, dan observasi. Sistem informasi jasa laundry dibutuhkan untuk efektifitas manajemen data supaya proses pengolahan data tersistematis. Sistem ini membuat seluruh manajemen laundry menjadi efisien dan sistematis. Penggunaan SMS gateway pada sistem ini dapat melengkapi transaksi pengambilan pakaian apabila struk pembayaran hilang.
\end{abstract}

Kata kunci-Throw-Away Prototype, Laundry, SMS Gateway

\begin{abstract}
The number of competition in the laundry service business makes laundry owners have to make policies for business progress. In terms of data processing, the laundry business is not too concerned with data management, both in terms of customer data transactions or delivery of customer goods. Unsystematic data management also causes frequent mistakes in bookkeeping. The purpose of this research is laundry service information system to help improve the performance of the admin in making reports, and making notifications for customers with an SMS gateway when their clothes are finished. The development of this web based laundry service information system uses the throw-away prototyping software development method with the stages of needs analysis, prototype development, prototype evaluation, system specifications, system programs, system validation, and application installation. In making this web-based laundry service information system using data collection methods conducted interviews, literature studies, and observations. Laundry service information systems are needed for data management effectiveness so that the data processing process is systematic. This system makes the entire laundry management efficient and systematic. The use of an SMS gateway in this system can complete the clothes collection transaction if the receipt is lost.
\end{abstract}

Keywords-Throw-Away Prototype, Laundry, SMS Gateway 


\section{PENDAHULUAN}

B erbagai jenis bisnis telah muncul dan menyebar keseluruh penjuru dunia saat ini, dikarenakan kebutuhan masyarakat yang semakin meningkat. Salah satu bisnis yang tumbuh pesat menjamur adalah usaha laundry. Usaha jasa laundry adalah yang menyediakan service jasa cuci bahan tekstil dalam bentuk pakaian karena banyak konsumen yang tidak sempat mencuci pakaiannya sendiri karena kesibukan atau hal-hal aktifitas lainnya. Laundry sebagai kata benda yang mengacu pada tindakan mencuci bahan tekstil atau pakaian dan tempat dimana mencuci dilakukan [1]. Dalam hal pengolahan data, usaha laundry tidak terlalu mementingkan manajemen data baik dalam hal transaksi data pelanggan atau penyerahan barang pelanggan. Manajemen data yang belum sistematis menyebabkan sering terjadi kekeliruan dalam pembukuan. Usaha laundry yang menjamur membuat para pelaku usaha harus berpikir lebih kreatif agar banyak konsumen tertarik memilih laundry. Hal-hal yang biasa ditawarkan oleh usaha laundry yaitu cuci lengkap yaitu cuci sampai pakaian kering kemudian dilakukan setrika rapih pakaian, cuci pakaian sampai kering saja, maupun setrika saja, lalu antar-jemput pakaian di rumah pelanggan dan biaya yang murah dengan kualitas kebersihan pakaian yang bagus [2]. Banyak pelaku usaha laundry yang tidak terlalu memikirkan manajemen data secara sistematis padahal saat ini data adalah sebuah harta karun yang jika diproses dengan fakta-fakta dapat berubah menjadi informasi yang berharga dan memiliki nilai jual.

Sebuah usaha penelitian melakukan development aplikasi laundry mengolah data menjadi informasi berharga yaitu mempermudah pelanggan dalam mencari tempat laundry terdekat dengan kualitas terbaik bagi pemilik jasa laundry hal ini dilakukan untuk mempromosikan usahanya [3]. Penelitian lainya adalah development sebuah jasa laundry banyak manfaatnya bagi pemilik karena jasa laundry begitu diminati padahal melakukan hal yang mudah saja seperti halnya mencuci dan menyetrika, tetapi ketika ada waktu luang pelanggan lebih memilih untuk istirahat atau melakukan kegiatan lain untuk refreshing dalam rangka menghilangkan kejenuhan [4]. Penerapan sistem manual menjadi sistem komputerisasi pada laundry diperluhkan guna memberi efektifitas layanan kepada pelanggan juga mempermudah petugas dalam membuat laporan dan juga bisa meminimalkan kesalahan data yang di akibatkan oleh kesalahan dalam pencatatan data transaksi pelayanan jasa [5]. Menurut Khoirunnissa sistem informasi jasa laundry dibutuhkan untuk mempermudah pengolahan dan pencatatan data secara akurat dan realtime, dengan adanya sistem ini, manajemen data maupun keuangan laundry dapat di proses ke dalam sebuah sistem yang terkomputerisasi [6]. Menurut Simargolang merancang aplikasi laundry pada usaha toko bernama Pelangi Laundry dapat memberikan profesional services dengan mengurangi kesalahan yang mungkin bisa terjadi dengan memberikan informasi yang update yang ditawarkan kepada pelanggan, efektifitas pengolahan laporan keuangan akurat juga tepat, dan antar jemput services laundry yang cepat dan terpercaya kepada pelanggan [1]. Triangga dan Ali di dalam penelitian mereka menjelaskan perancangan sistem informasi jasa laundry berbasis desktop sebagai solusi yang baik bagi pelayanan jasa di Toko Quin's Laundry, hal-hal yang diproses oleh sistem diantaranya manajemen data pelanggan, laporan transaksi pelanggan lalu laporan keuangan toko.

Berdasarkan latar belakang dan menimbang permasalahan manajemen data usaha laundry dan sebagai usaha meningkatkan service quality pada usaha laundry, pada penelitian ini dirancang sebuah aplikasi berbasis website terintegrasi dengan SMS gateway. Tujuan dari penelitian ini adalah ini membuat seluruh manajemen laundry menjadi efisien dan sistematis. Penggunaan SMS gateway pada sistem ini dapat melengkapi transaksi pengambilan pakaian apabila struk pembayaran hilang [7]. 


\section{METODE PENELITIAN}

Metode Throw-Away Prototyping atau dikenal rapid prototyping pertama kali ditemukan oleh McCracken dan Wolfe. Pendekatan prototyping terdapat dua macam yaitu Throw-Away Prototyping dan evolutionary prototyping [8]. Sebuah pendekatan prototipe dapat digunakan dalam pengembangan perangkat lunak, hal ini dilakukan untuk mengantisipasi proses perubahan yang mungkin terjadi [9]. Pendekatan evolutionary prototyping adalah pengembangan sistem dengan cara tidak mengetahui spesifikasi detail sistem di awal tahap pengembangan. Detail spesifikasi sistem yang abstrak membuat pemeriksaan detail sistem tidak dilakukan. Proses validasi dapat dilakukan dengan mendemonstrasikan saat sistem sudah spesifik. Pendekatan throw-away prototyping adalah spesifikasi detail kebutuhan sistem sejak awal sudah diketahui terlebih dahulu, sehingga pada pendekatan ini dapat mengurangi resiko kebutuhan sistem yang tidak terpenuhi [10]. Metodologi throw-away prototyping secara keseluruhan menggunakan fase analisis yang bertujuan untuk mengumpulkan informasi dan mengembangkan ide-ide untuk konsep sistem [11]. Tahap-tahap throw-away prototyping dapat dilihat pada gambar 1 .

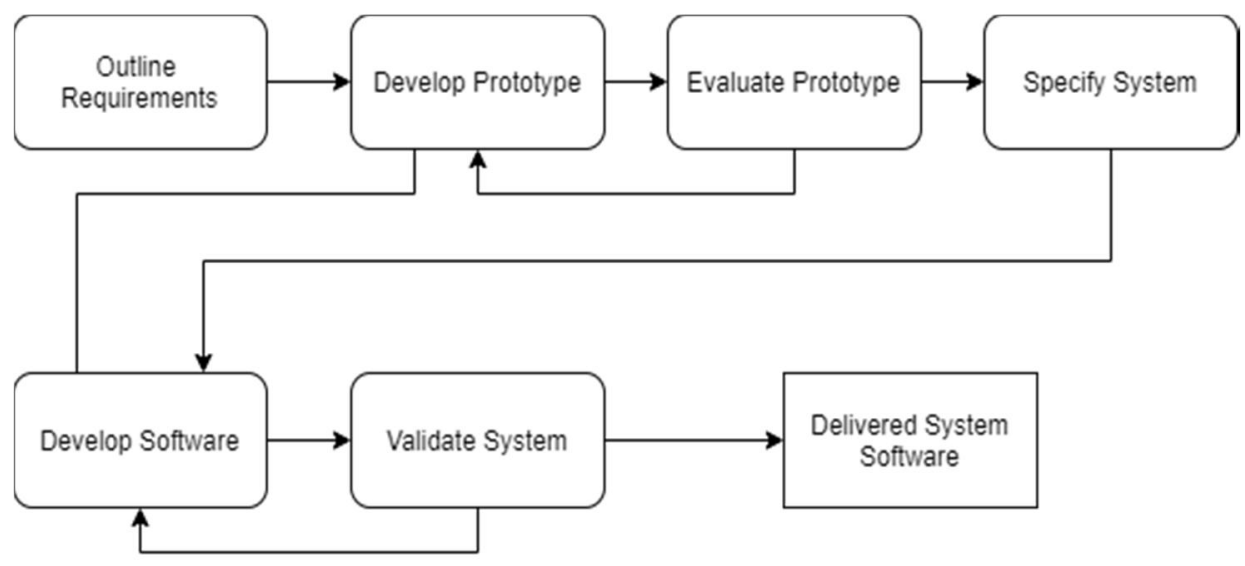

Gambar 1. Tahapan Throw-Away Prototyping [8]

\subsection{Tahap Eksplorasi Kebutuhan}

Tahapan eksplorasi adalah melakukan pencatatan keperluan dasar user akan sistem. Setiap spesifikasi yang tercantum dibentuk dalam User Stories. Hasil dari tahapan awal ini yaitu mengetahui dokumentasi atas ruang lingkup sistem, visi dan juga lingkup job desc.

\section{2 Membuat Prototype}

Tahapan membuat prototype dalah membuat sistem dengan memanfaatkan alat bantu. Pada tahap ini sangat bergantung pada tahapan sebelumnya yang didapatkan berdasarkan hasil wawancara, analisis kebutuhan ataupun studi literature.

\section{3 Evaluasi Prototype}

Pada tahap ini hasil prototype sistem kemudian ditunjukan kepada user, hal ini dilakukan dengan maksud agar user untuk mengetahui karakteristik dari prototype [12]. Pada kesempatan ini user berbicara tentang kebutuhan kepada developer. Jika prototype sistem diterima, selanjutnya yaitu development sistem, jika ada koreksi, maka kembali ke tahapan sebelumnya yaitu membuat prototype sampai user setuju dan kemudian diamati ulang dengan penilaian standar user. 


\section{4 Detail Spesifikasi Sistem}

Pada tahap ini melakukan kebutuhan daftar spesifikasi software atau hardware yang diperlukan dalam pembuatan sistem sesuai prototype. Daftar spesifikasi adalah menentukan penggunaan software tertentu, hardware tertentu, bahasa pemrograman yang digunakan, perancangan database dan juga harus sesuai dengan kebutuhan user dengan metode pengembangan yang telah ditentukan.

\section{5 Develop Software}

Tahapan transformasi prototype ke dalam bahasa pemrograman dan juga melakukan integrasi database. Setelah proses pembuatan aplikasi dalam bentuk program sistem selesai aksi kelanjutan adalah tahap sistem validation.

\section{6 Validasi Sistem}

Pengujian sistem agar sesuai dengan hasil yang diharapkan. Pengujian dengan beberapa metode dapat dilakukan untuk menetapkan masukan yang menjadi input sistem memberikan keluaran dengan keinginan user.

\section{7 Instalasi Aplikasi atau Sistem}

Develop software yang telah melalui tahap uji dan sudah sesuai dengan keinginan user akan ditetapkan release agar dapat dimanfaatkan sesuai dengan keinginan tujuan user.

\section{HASIL DAN PEMBAHASAN}

\subsection{Eksplorasi Kebutuhan}

Pada pembuatan aplikasi usaha laundry berbasis web ini telah ditetapkan dasar keperluan user yaitu kebutuhan user yang meliputi skenario kebutuhan admin, dan pelanggan. Tabel esksplorasi kebutuhan dapat dilihat pada tabel 1.

Tabel 1. Eksplorasi Kebutuhan Admin dan Pelanggan

\begin{tabular}{|c|l|l|}
\hline No. & \multicolumn{1}{|c|}{ Admin } & \multicolumn{1}{|c|}{ Pelanggan } \\
\hline 1 & Dapat mengelola data jenis pakaian & $\begin{array}{l}\text { Dapat mengecek data } \\
\text { transaksi }\end{array}$ \\
\hline 2 & $\begin{array}{l}\text { Dapat mengelola data jenis paket } \\
\text { service }\end{array}$ & $\begin{array}{l}\text { Dapat menerima } \\
\text { pemberitahuan lewat SMS }\end{array}$ \\
\hline 3 & Dapat mengelola data pelanggan & - \\
\hline 4 & Dapat mengelola data transaksi & - \\
\hline 5 & Dapat membuat laporan bulanan & - \\
\hline 6 & $\begin{array}{l}\text { Dapat mengirimkan SMS sebagai } \\
\text { pemberitahuan bahwa pakaian dapat } \\
\text { diambil karena telah selesai laundry }\end{array}$ & - \\
\hline
\end{tabular}

\subsubsection{Flowmap Prototype Sistem}

Prototype system menjadi alternatif pemecahan masalah apabila sistem banyak mengalami perubahan, membuat sistem informasi jasa laundry berbasis web, dengan harapan adanya sistem ini proses pelayanan menjadi lebih baik. Pada sistem ini terdapat beberapa menu yang diharapkan dapat membantu proses pelayanan dan pembuatan laporan pada laundry yang bisa digunakan dengan mudah. Berikut Flowmap sistem usulan. 
Jatisi

ISSN 2407-4322

Vol. 7, No. 3, Desember 2020, Hal. 656-667 E- ISSN 2503-2933

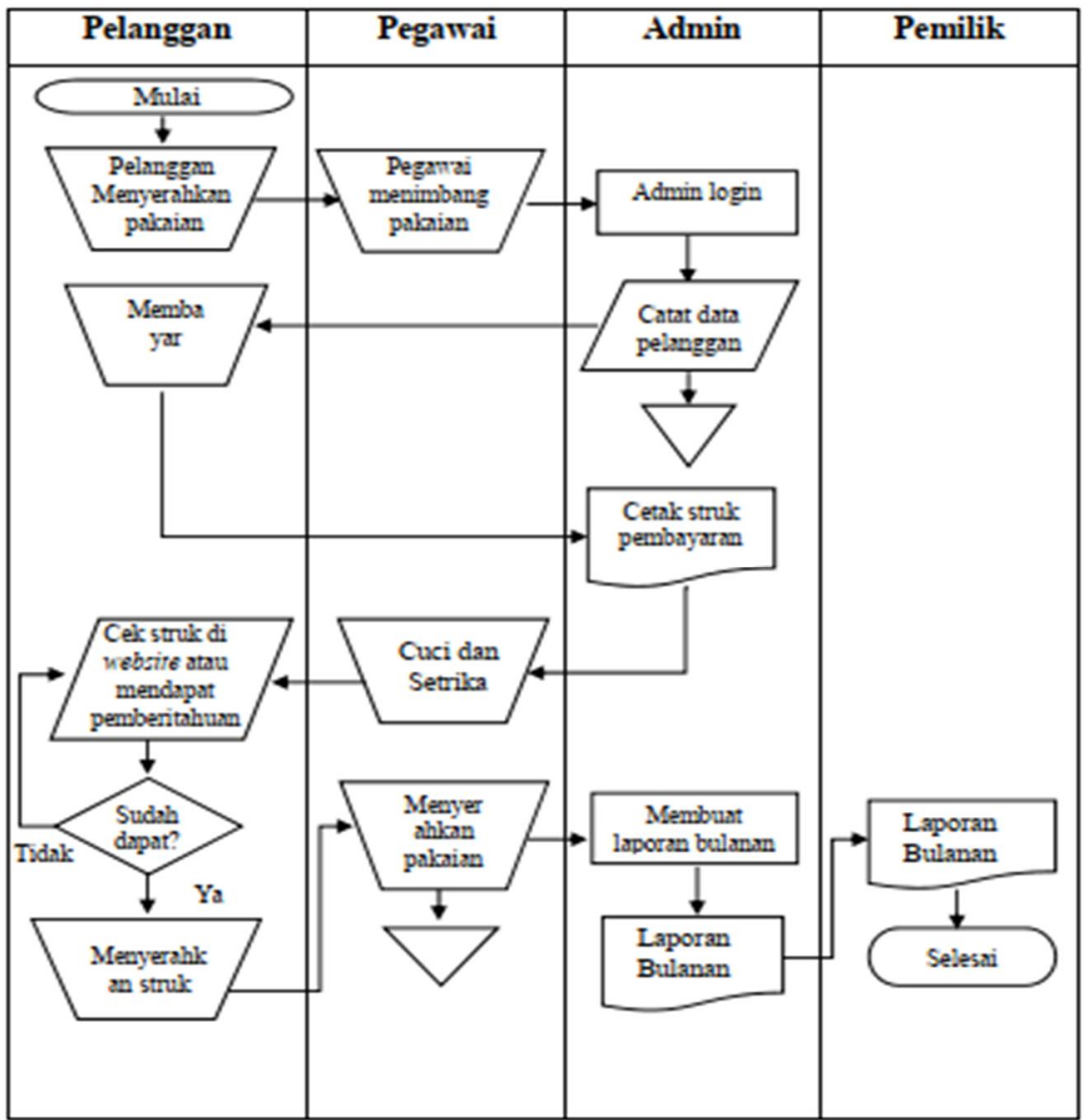

Gambar 2. Flowmap Sistem Usulan

\subsubsection{Use Case Prototype Sistem}

Diagram di bawah ini adalah gambaran aktor yang berjalan di dalam proses sistem. Penjelasan use case diagram ini dapat dilihat pada gambar 3 dan tabel 2 berikut: 


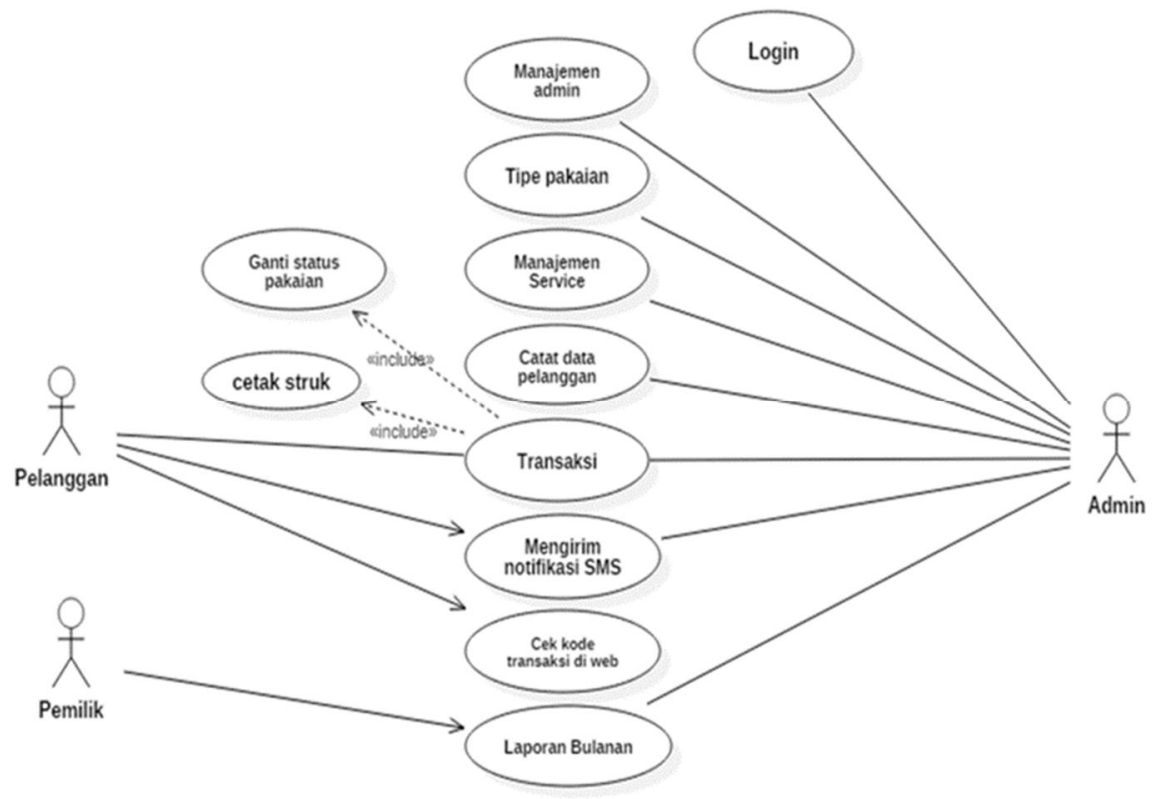

Gambar 3. Use Case Diagram

Tabel 2. Skenario Use Case untuk Sistem Usulan

\begin{tabular}{|c|c|c|c|}
\hline No & Nama Use Case & Skenario Input dan Hasil Ouput & Aktor \\
\hline 1 & Login & $\begin{array}{l}\text { Aktor menggunakan halaman login dengan } \\
\text { input username dan password yang benar, } \\
\text { untuk akses login dashboard admin }\end{array}$ & administrasi \\
\hline 2 & Manajemen $a d m i n$ & $\begin{array}{l}\text { dengan input data berupa nama admin, } \\
\text { email, username, dan password, proses ini } \\
\text { digunakan aktor untuk hasil output } \\
\text { menambahkan admin pada sistem }\end{array}$ & administrasi \\
\hline 3 & Tipe Pakaian & $\begin{array}{l}\text { dengan input data berupa kode paket, } \\
\text { nama paket, dan harga paket, proses ini } \\
\text { digunakan aktor untuk hasil output } \\
\text { menambahkan tipe pakaian pelanggan di } \\
\text { sistem }\end{array}$ & administrasi \\
\hline 4 & $\begin{array}{l}\text { Manajemen } \\
\text { Service }\end{array}$ & $\begin{array}{l}\text { dengan input data berupa paket services } \\
\text { dan harga, proses ini digunakan aktor } \\
\text { untuk hasil output menambahkan proses } \\
\text { service pada pelanggan di sistem }\end{array}$ & administrasi \\
\hline 5. & $\begin{array}{l}\text { Catat data } \\
\text { pelanggan }\end{array}$ & $\begin{array}{l}\text { dengan input data berupa nama lengkap, } \\
\text { alamat, dan nomor handphone, proses } \\
\text { aktor untuk melakukan hasil output } \\
\text { pendataan pelanggan untuk meminta } \\
\text { informasi tentang pelanggan. }\end{array}$ & $\begin{array}{l}\text { Administrasi } \\
\text { dan } \\
\text { pelanggan }\end{array}$ \\
\hline 6. & Transaksi & $\begin{array}{l}\text { Proses pelanggan melakukan proses } \\
\text { pemilihan jasa paket service } r \text { dan } \\
\text { pembayaran pada admin untuk } \\
\text { melanjutkan transaksi. }\end{array}$ & $\begin{array}{l}\text { administrasi } \\
\text { dan } \\
\text { pelanggan }\end{array}$ \\
\hline
\end{tabular}




\begin{tabular}{|c|c|c|c|}
\hline 7. & Cetak Struk & $\begin{array}{l}\text { dengan input data berupa klik button cetak, } \\
\text { proses ini aktor memberikan } \\
\text { mengeluarkan output struk kepada } \\
\text { pelanggan untuk pengambilan pakaian. }\end{array}$ & $\begin{array}{l}\text { administrasi } \\
\text { dan } \\
\text { pelanggan }\end{array}$ \\
\hline 8. & $\begin{array}{l}\text { Ganti status } \\
\text { pakaian }\end{array}$ & $\begin{array}{l}\text { dengan input data berupa klik button status } \\
\text { transaksi, proses ini aktor melakukan } \\
\text { perubahan status pakaian di sistem } \\
\text { agar pelanggan bisa melihat status } \\
\text { pakaiannya }\end{array}$ & administrasi \\
\hline 9. & $\begin{array}{l}\text { Cek Kode } \\
\text { transaksi }\end{array}$ & $\begin{array}{l}\text { dengan input data berupa kode transaksi } \\
\text { Proses ini menghasilkan output dapat aktor } \\
\text { dapat mengecek no kode transaksi/ } \\
\text { transaksi di website. }\end{array}$ & pelanggan \\
\hline 10. & $\begin{array}{l}\text { Mendapat } \\
\text { Notifikasi SMS }\end{array}$ & $\begin{array}{l}\text { dengan input data berupa proses transaksi } \\
\text { pada sisi admin, proses ini admin } \\
\text { mengirimkan output yaitu notifikasi via } \\
\text { SMS saat pakaian telah selesai ke } \\
\text { pelanggan. }\end{array}$ & $\begin{array}{l}\text { administrasi } \\
\text { dan pelanggan }\end{array}$ \\
\hline 11. & Laporan Bulanan & $\begin{array}{l}\text { Proses ini admin membuat laporan } \\
\text { bulanan untuk pemilik. }\end{array}$ & $\begin{array}{l}\text { Administrasi } \\
\text { dan Pemilik }\end{array}$ \\
\hline
\end{tabular}

\section{2 Membuat Prototype}

Pada tahapan ini membuat rancangan tampilan sistem informasi usaha laundry yang dibuat menggunakan software Balsamic Mockup. Rancangan tampilan manajemen data pada tampilan sisi admin ada pada tabel 3 .

Tabel 3. Rancangan Tampilan pada Sisi Admin Aplikasi Laundry Berbasis Website

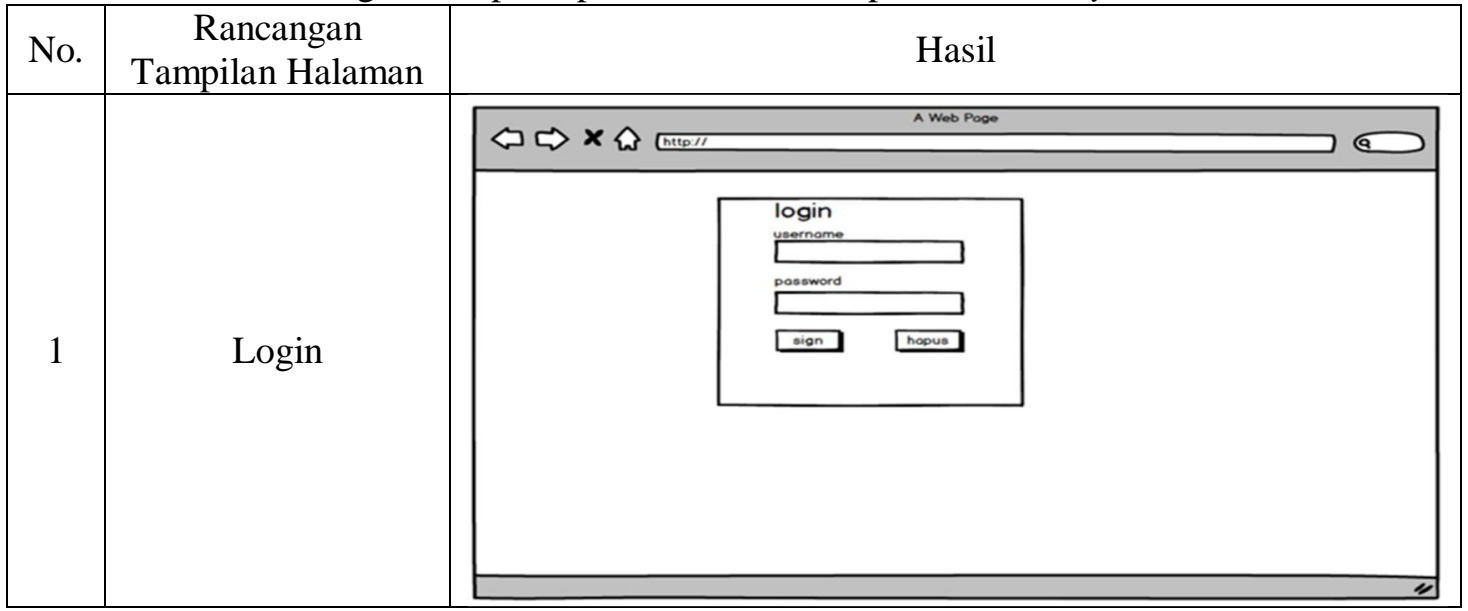




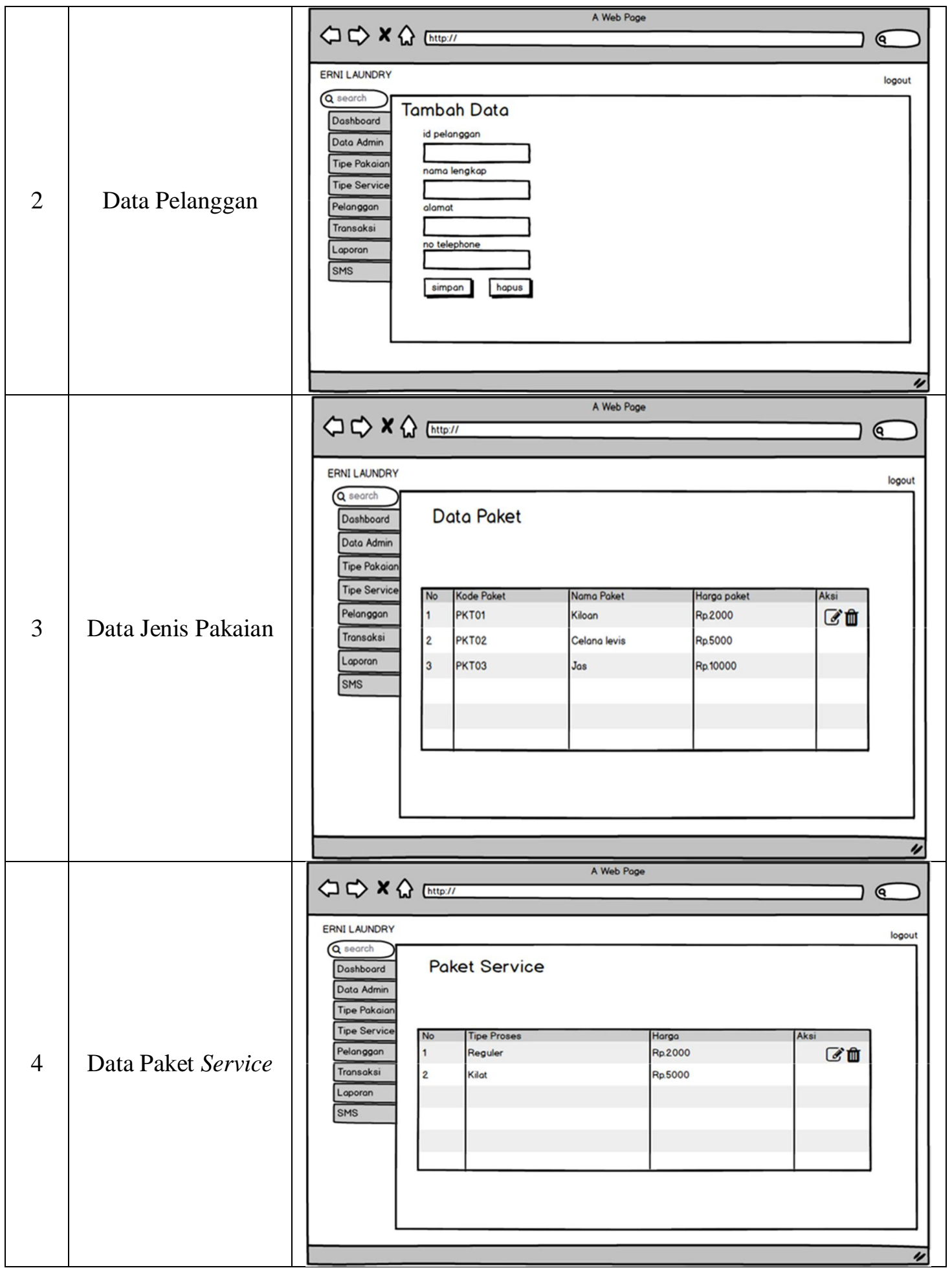


Jatisi

ISSN 2407-4322

Vol. 7, No. 3, Desember 2020, Hal. 656-667 E- ISSN 2503-2933

664

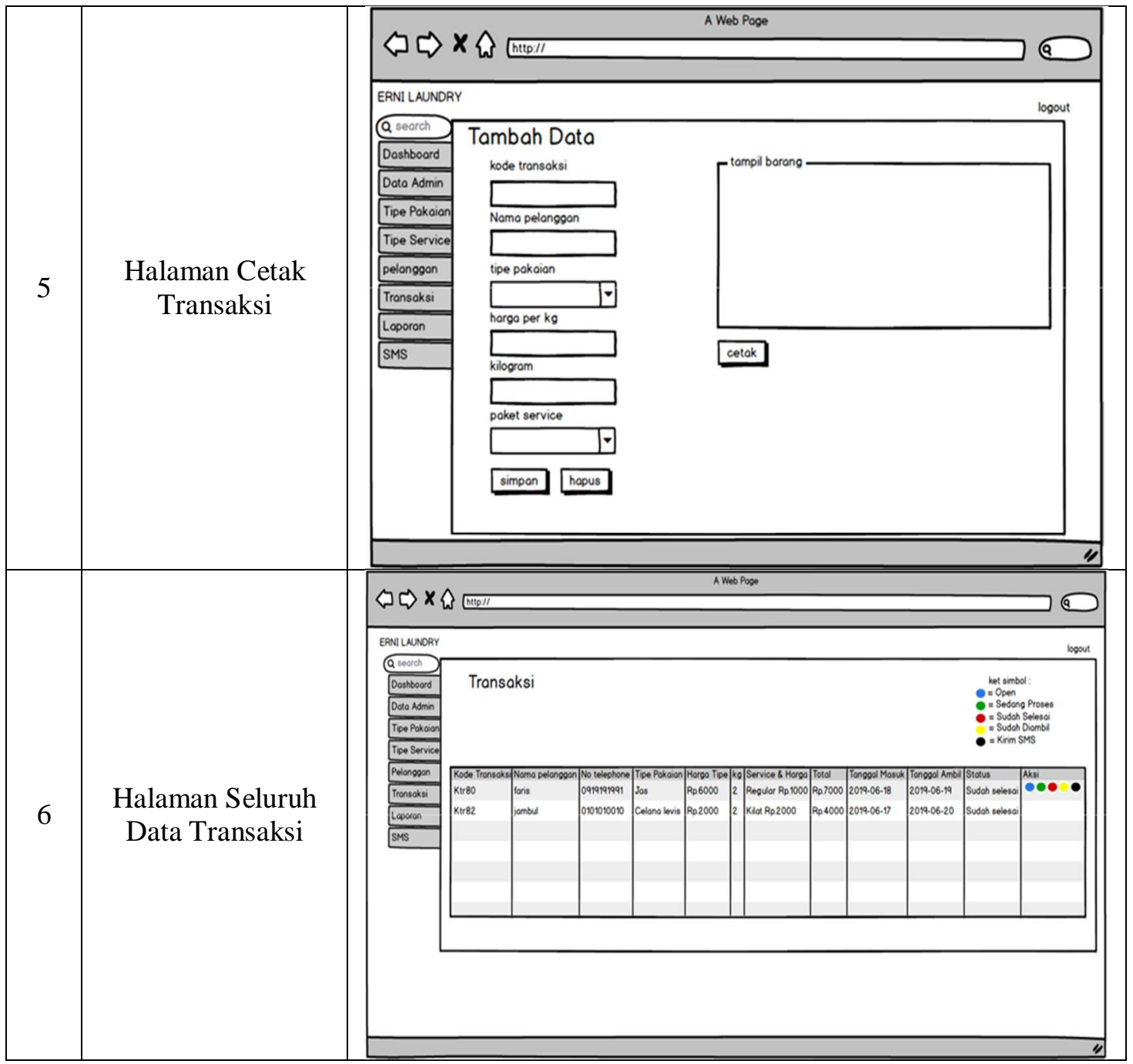

\section{3 Spesifikasi Sistem}

Aplikasi usaha laundry berbasis website diantaranya menggunakan software Balsamic Mockup untuk membuat rancangan tampilan, Star UML untuk pembuatan use case diagram, Sistem operasi windows 7, web server XAMPP, software MySQL untuk membuat database, software sublime sebagai teks editor bahasa pemrograman. Hardware yang digunakan diantaranya Processor intel Core i 3 dengan RAM 4GB dan storage harddisk 500GB. Gambar 4 menunjukan rancangan database yang dibuat. 


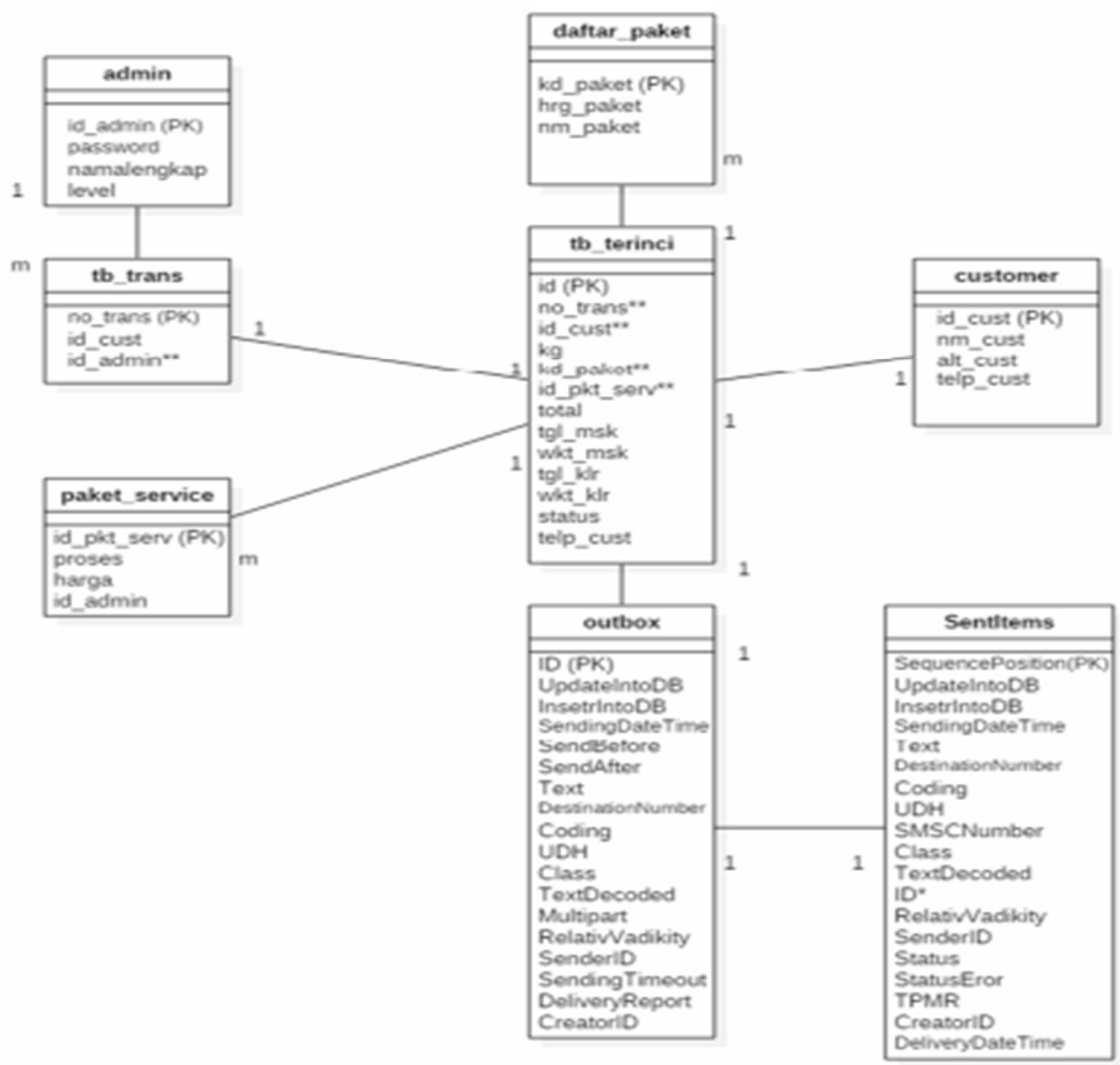

Gambar 4. Rancangan Database yang Dibuat

\section{4 Develop Software}

Transformasi dari prototype yang telah dibuat menggunakan bahasa pemrograman pendukung berbasis website seperti PHP, HTML, CSS dan program aplikasi Apache MySQL untuk program databasenya.

\section{5 Implementasi Aplikasi}

Dalam Tahap ini yaitu menghubungkan MySQL dengan PHP menggunakan aplikasi Xampp sebagai server, selanjutkan hal yang dilakukan adalah menghubungkan sistem informasi jasa laundry. Aplikasi pada sisi pelanggan ada pada gambar 5. 


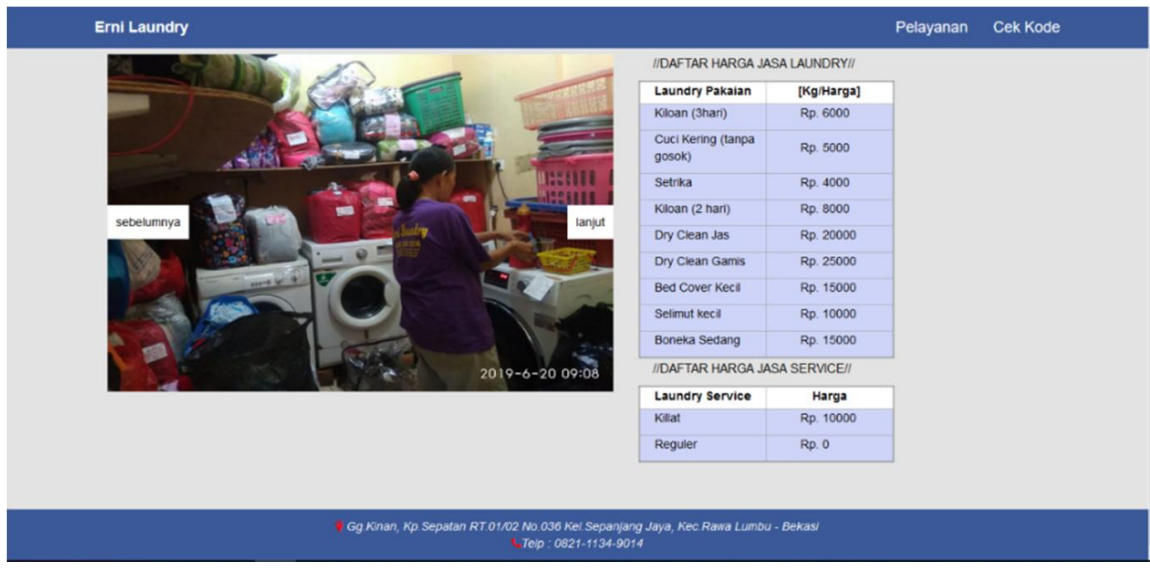

Gambar 5. Halaman Utama Pelanggan

Pada sisi kanan atas halaman terdapat button cek kode transaksi, pelanggan bisa mengecek barang transaksi miliknya dengan menggunakan kode transaksi.

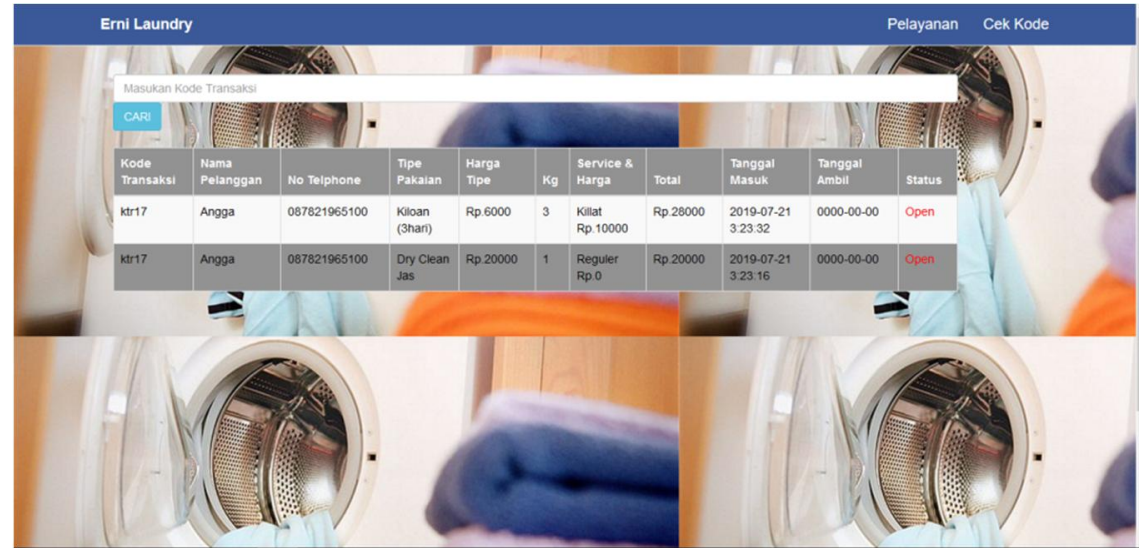

Gambar 6. Halaman Cek Kode Transaksi

\section{KESIMPULAN}

Sistem informasi jasa laundry berbasis web membuat data pelanggan tidak memiliki duplikasi dan sistem ini dapat membantu dalam pembuatan laporan pembukuan yang dapat memperlihatkan dengan detail sebuah transaksi dan membantu penyampaian informasi antara pegawai laundry dengan pelanggan sehingga meminimalisir kesalahpahaman informasi. SMS gateway dapat melengkapi transaksi pengambilan pakaian apabila struk pembayaran hilang.

\section{SARAN}

Penyempurnaan sistem informasi jasa laundry berbasis web terintegrasi SMS gateway dan SMS Location Based Advertising (LBA) yaitu bagaimana operator mengirimkan SMS promo kepada pelanggan di lokasi tertentu yang telah dipilih. Hal ini dapat meningkatkan transaksi usaha karena dapat memberi tahu pelanggan berupa promo laundry, pelayanan yang ada pada laundry dimana lokasi usaha laundry, meskipun pelanggan belum pernah datang ke lokasi toko sama sekali ataupun bukan pelanggan tetap laundry. 


\section{DAFTAR PUSTAKA}

[1] M. Y. Simargolang and N. Nasution. 2018, "Aplikasi Pelayanan Jasa Laundry Berbasis WEB (Studi Kasus: Pelangi Laundry Kisaran)," J. Teknol. Inf., Vol. 2, No. 1, p. 9, doi: 10.36294/jurti.v2i1.402.

[2] Kamil. 2016, "Pembangunan Sistem Informasi Pelayanan Jasa Laundry Berbasis Web Dengan Fitur Mobile pada 21 Laundry Padang," Semin. Nas. Sains dan Teknol. Fak. Tek. Univ. Muhammadiyah Jakarta, Vol. 8, No. November, pp. 1-9.

[3] E. Susanto, T. H. Utami, and D. Hermanto. 2019, "Sistem Informasi Pemesanan Laundry Berbasis Android di Kota Palembang," JATISI (Jurnal Tek. Inform. dan Sist. Informasi), Vol. 5, No. 2, pp. 158-168, doi: 10.35957/jatisi.v5i2.144.

[4] S. Rosyida and V. Riyanto, 2019, "Sistem Informasi Pengelolaan Data Laundry pada Rumah Laundry Bekasi,” JITK (Jurnal Ilmu Pengetah. dan Teknol. Komputer), Vol. 5, No. 1, pp. 29-36, doi: 10.33480/jitk.v5i1.611.

[5] Z. A. Isnaini, "Sistem Informasi Pelayanan Jasa Laundry Berbasis Desktop pada Quick Laundry Semarang," 2015.

[6] R. Khoirunnisa, R. R. Isnanto, and K. T. Martono. 2016, "Pembuatan Aplikasi Web Manajemen Laundry dan Integrasi Data dengan Web Service," J. Teknol. dan Sist. Komput., Vol. 4, No. 1, p. 93, doi: 10.14710/jtsiskom.4.1.2016.93-101.

[7] Felicia Sylviana, Sherly Christina, and Sunartie, 2019, "Aplikasi Pemesanan Laundry Berbasis SMS Gateway," J. Teknol. Inf. J. Keilmuan dan Apl. Bid. Tek. Inform., Vol. 13, No. 2, pp. 12-17, doi: 10.47111/jti.v13i2.248.

[8] Y. I. Meilani, P. Studi, and S. Informasi, 2019, "Implementasi Metode Proyotyping dan Twitter Bootstrap Responsive pada Sistem Pembelajaran Bagi Siswa/I SMA di Palembang," Vol. 10, No. 2, pp. 753-762.

[9] R. Khalida, 2017, "Augmented Reality: Simulasi Terapi Low Back Pain," Pdfs.Semanticscholar.Org, 2017.Vol. 17, No. 3, pp. 127-136.

[10] S. Kosasi, 2018, "Perancangan Prototipe Sistem Pemesanan Makanan dan Minuman Menggunakan Mobile Device," Vol. 1, No. January, pp. 175-187,

[11] I. G. Ngurah, A. Cahyadi, I. Bagus, and M. Mahendra, 2020, "Pengembangan Aplikasi Monitoring Inventaris Kelas Dengan Sistem Barcode,” Vol. 8, No. 4, pp. 525-527.

[12] R. Muzawi, "Rancang Bangun Prototype Pengontrolan Lampu Gedung STMIK AMIK Riau Berbasis IoT Menggunakan Rasberry Pi 3 Model B," JATISI (Jurnal Tek. Inform. dan Sist. Informasi), Vol. 5, No. 1, pp. 100-108, 2018, doi: 10.35957/jatisi.v5i1.127. 